\title{
Desempenho de cortadores de base para colhedoras de cana-de-açúcar com lâminas serrilhadas e inclinadas
}

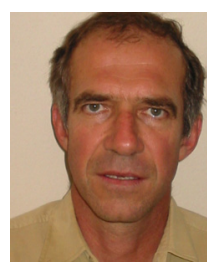

Roberto da C. Mello ${ }^{1} \&$ Harry Harris ${ }^{2}$

1 CEA/IAC. CP 26, CEP 13201-970, Jundiaí, SP. Fone: (11) 4582-8155. E-mail: rcmello@iac.br (Foto)

2 University of Southern Queensland, Australia. E-mail: harrish@tpg.com.au

Protocolo 151 - 17/10/2002 - Aprovado em 23/6/2003

\begin{abstract}
Resumo: O Brasil é o maior produtor mundial de cana-de-açúcar. A mecanização da colheita tornou-se uma necessidade dos tempos modernos, mas perdas de 10 a $15 \%$ são freqüentes quando a cana é colhida crua. A deflexão e o corte de base são responsáveis por danos na cana colhida e na soqueira. As colhedoras cortam a cana em sua base pelo impacto, usando dois discos rotativos com múltiplas lâminas. A alternativa para o corte por impacto é o corte por deslizamento. Foram estudados a influência do tipo de lâmina (inclinada para frente e para trás) e o passo do perfil serrilhado ( 3 e $7 \mathrm{~mm}$ ) na presença de um momento fletor causado pela ação do rolo defletor. Uma lâmina padrão foi utilizada como testemunha e feitas quatro repetições para cada tipo de corte. Foram comparados os danos causados na cana e a energia gasta para cada corte. As lâminas inclinadas para a frente com passo serrilhado de $3 \mathrm{~mm}$, foram as que apresentaram os melhores resultados.
\end{abstract}

Palavras-chave: cortador de base, colhedora de cana-de-açúcar, lâminas serrilhadas

\section{Performance of basecutter of sugarcane harvester with angled and serrated blades}

\begin{abstract}
Brazil is the world's largest sugarcane producer. The mechanized harvest became necessary for the modern times but losses of $10-15 \%$ are frequent when the sugarcane is harvested green. The knockdown and the basecutter are responsible for damages in the stalk and stool. The harvester cuts the cane at its base by an impact using a rotating disk with multiple blades. The alternative for the impact cut is the slicing cut. The influence of the type of blades (forward and backward) and the pitch of serration $(3$ and $7 \mathrm{~mm}$ ) in the presence of a flection moment caused by the action of the knockdown roller was studied. One standard blade was used as a reference and four replications were used for each type of cut. An experiment was conducted using a factorial design with two kinds of blades and two pitches of serration. The damages caused in the sugarcane and the energy spent on each type of cut were compared. The forward blade with serrated pitch of $3 \mathrm{~mm}$ presented the best result.
\end{abstract}

Key words: sugarcane harvesters, basecutter, serrated blades

\section{INTRODUÇÃO}

As colhedoras cortam a cana em sua base pelo impacto, usando um disco rotativo com múltiplas lâminas. O rolo defletor empurra a cana para frente antes de cortá-la, para facilitar a alimentação pelos rolos alimentadores.

De acordo com Ueno \& Izumi (1995) perdas de 10 a 15\% são freqüentes quando a cana é colhida crua (sem queima prévia). Kroes (1997) mostrou que os danos causados pelo cortador de base é o maior problema das colhedoras.

A deflexão e o corte de base são responsáveis por danos na cana colhida e na soqueira, causando grande volume de perdas, tanto de massa como por deterioração, além de facilitar $\mathrm{o}$ ataque de fungos e doenças na soqueira.

O trabalho de Kroes (1997) mostrou que, com o presente desenho do cortador de base, é impossível evitar tais perdas e danos. Portanto, os atuais cortadores de base das colhedoras de cana, além de causarem um alto volume de perdas de cana, também provocam redução na produtividade potencial devido aos danos ocasionados na soqueira.

Mello (2003) define, como alternativa para o corte por impacto, o corte por deslizamento (slicing cut). Segundo Person (1987) se houver um ângulo oblíquo entre a lâmina e o material a ser cortado, ocorrerá também um deslizamento e, estando o material aderido à lâmina, este será rompido por fricção. 
Segundo Kroes (1997) o corte por deslizamento não se aplica a cortadores de base para colhedoras de cana-de-açúcar, pois estes trabalham rente ou abaixo da superfície do solo, sendo impossível manter o perfil das lâminas amolado e, nestas condições, a cana acaba escorregando ao longo da lâmina sem ser cortada adequadamente.

Harris \& Mello (1999) sugeriram lâminas com perfil serrilhado para resolver este problema. Os perfis serrilhados, apesar de serem comuns, nada foi publicado a respeito e foi encontrada apenas uma referência (Chacellor, 1957); portanto, este artigo fornece também alguns dados sobre este tipo e perfil.

O principal objetivo deste trabalho é a comparação entre o corte por deslizamento feito com lâminas inclinadas para trás e para frente, na presença de deflexão.

\section{MATERIAL E MÉTODOS}

Uma série de testes de laboratório foi realizada no Sugar Research Institute em Mckay, Austrália. Uma estrutura construída por Kroes (1997) foi modificada para ser utilizada nesses testes (Figura 1).

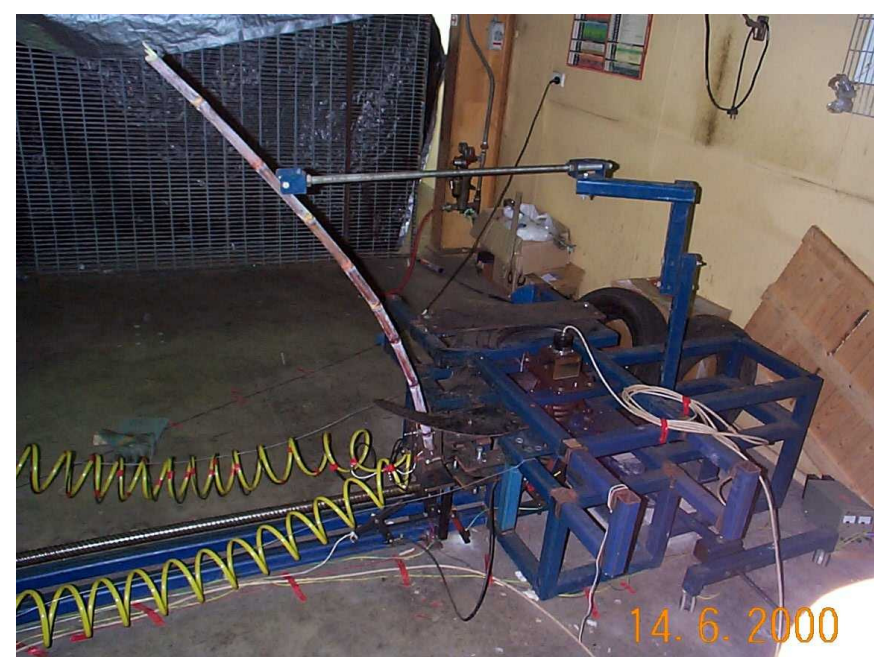

Figura 1. Estrutura construída por Kroes (1997) e modificada para os testes

A estrutura acima consta de um suporte para apoiar a cana, uma mola de torção para acelerar a lâmina e um braço para simular o efeito do rolo defletor. Um mecanismo de rosca, criado por uma furadeira manual, fornece a tensão na mola, que é disparada manualmente, acelerando a lâmina. Um Rotary Shaft Encoder (RSE) mede a velocidade da lâmina antes e após o corte.

Foram estudados a influência do tipo de lâmina (inclinada para frente e para trás) e o passo do perfil serrilhado (3 e $7 \mathrm{~mm}$ ) na presença de um momento fletor, para simular a ação do rolo defletor. Uma lâmina padrão foi utilizada como testemunha e feitas quatro repetições para cada tipo de corte.

Utilizou-se um planejamento estatístico do tipo Delineamento Inteiramente Casualizado, além do teste de Tukey, para comparação das médias dos danos causados na cana e da energia específica gasta para cada corte.

Para se determinar os danos causados na cana, foi adaptada uma tabela construída por Kroes (1997) e mostrada na Figura 2.
A energia foi determinada pela seguinte equação:

$$
\mathrm{E}=\mathrm{J}\left(\omega_{\mathrm{i}}^{2}-\omega_{\mathrm{f}}^{2}\right) / 2
$$

em que:

J - momento de inércia da lâmina mais as peças móveis

$\omega_{i}$ - velocidade angular inicial

$\omega_{\mathrm{f}}$ - velocidade angular final

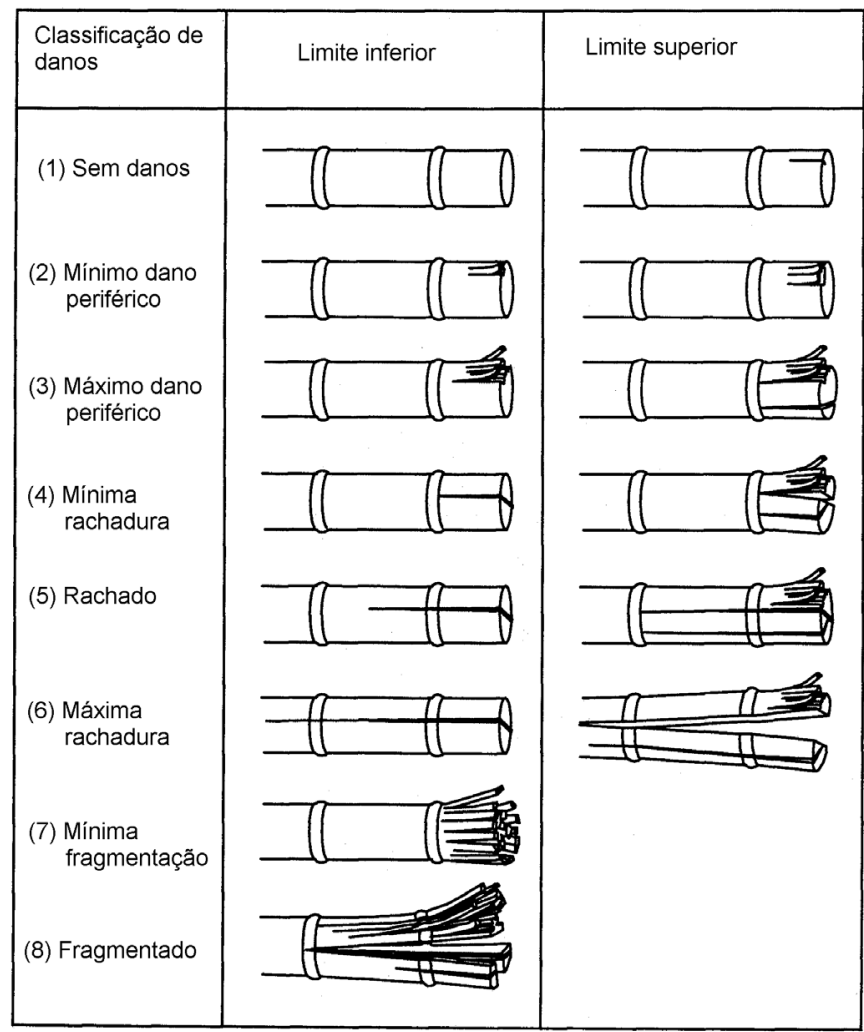

Figura 2. Tabela construída por Kroes (1997) e adaptada para classificação de danos

A energia específica foi determinada dividindo-se a energia pela área cortada.

Com base em estudo cinemático realizado por Harris e Mello (1999) foram definidos dois cortadores de base com lâminas curvas, inclinadas para frente e para trás, como mostra a Figura 3.

Baseado no desenho dos cortadores de base da Figura 3, um conjunto de lâminas foi desenhado e construído para ser adaptado na estrutura de testes da Figura 1. As lâminas foram construídas em aço carbono (1020) com $4 \mathrm{~mm}$ de espessura e o perfil serrilhado foi feito com fresa de $90^{\circ}$. As lâminas são apresentadas na Figura 4.

Pode-se observar um furo na parte superior e cinco furos na parte inferior das lâminas (Figura 4), o que possibilita mudanças no ângulo de ataque (ângulo oblíquo). Neste trabalho, os ângulos foram fixos sendo $0^{\circ}$ para a lâmina standard (corte por impacto), $63^{\circ}$ de inclinação para trás e $44^{\circ}$ de inclinação para frente.

\section{RESULTADOS E DISCUSSÃO}

A ação do rolo defletor causa um momento fletor no caule da cana que, em alguns casos, excede a sua resistência (Kroes, 


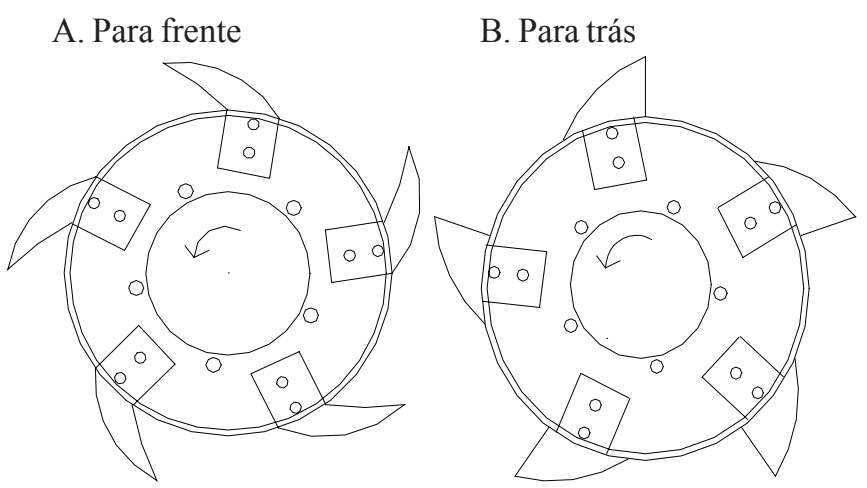

Figura 3. Cortador de base com lâminas inclinadas

A. Lâmina inclinada para trás

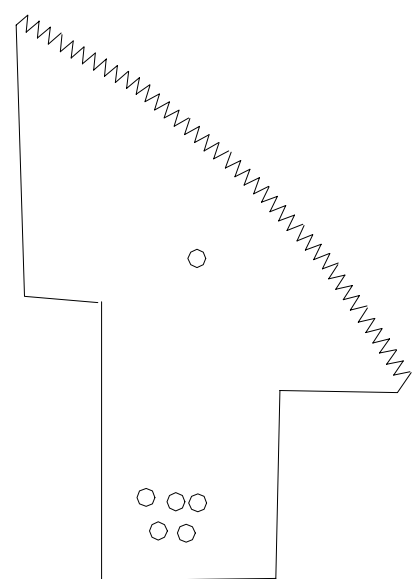

B. Lâmina inclinada para frente

Figura 4. Lâminas utilizadas no teste

1997). Quando um corpo está sujeito a um momento fletor, aparecem forças internas de tração e compressão, como mostra a Figura 5.

Dependendo do tipo de lâmina utilizada (standard, inclinada para frente e para trás) o corte se inicia em diferentes posições, como indica a Figura 6.

Com a lâmina standard, ambas as áreas são cortadas ao mesmo tempo, enquanto a lâmina inclinada para trás inicia o corte pela zona tracionada e a lâmina inclinada para a frente, $\mathrm{o}$ inicia pela zona comprimida.

A lâmina standard produz o corte por impacto. Person (1987) definiu o corte por impacto como sendo um tipo de corte onde a força é estritamente normal contra a superfície da cana. Pelo fato da força ser normal no corte por impacto, as fibras são deslocadas e rompidas principalmente por uma força de tração, e toda a cana está envolvida no processo de corte ao mesmo tempo. $\mathrm{O}$ deslocamento das fibras causa grandes danos à cana.

Nas lâminas inclinadas para frente e para trás, além da força normal existe, também, uma força tangencial, que causa uma fricção entre a lâmina e as fibras e estas são rompidas sobretudo por cisalhamento, causando menores danos à cana, pelo fato das fibras se deslocarem menos e poucas fibras estarem envolvidas no processo de corte ao mesmo tempo.

Como a maioria dos danos ocorre na parte final do corte, pode-se observar que, quando esta parte está sendo tracionada, os danos são menores e com isto foi possível se concluir que é mais fácil cortar, causando menores danos, um material

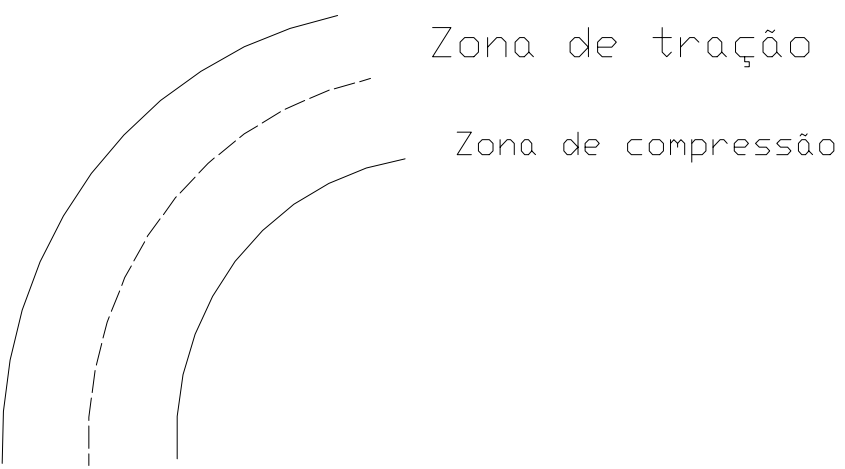

Figura 5. Corpo submetido a momento fletor

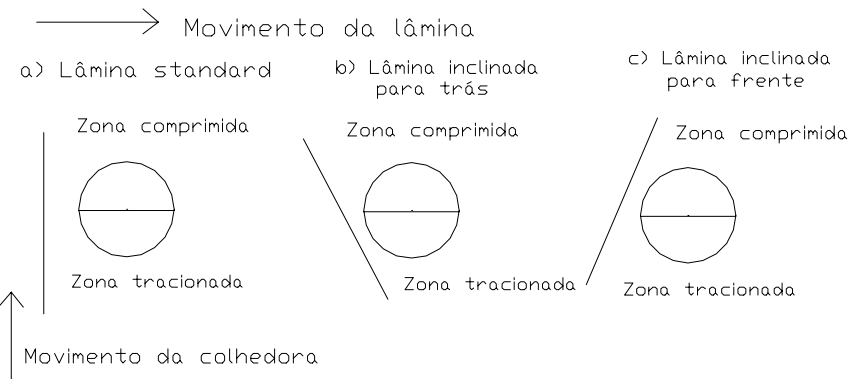

Figura 6. Posição do corte em função do tipo de lâmina

que está sendo tracionado que um material que está sendo comprimido.

A Figura 7 exibe um corte com a lâmina standard, em que é possível se observar os danos causados à cana. Segundo Kroes (1997) as lâminas standard causam danos classificados como "rachado" ou número 5.

A Figura 8 mostra um corte com lâminas inclinadas para trás na qual é possível se observar a propagação do corte. Nota-se que o corte teve início pela zona tracionada, como indica a Figura 6.

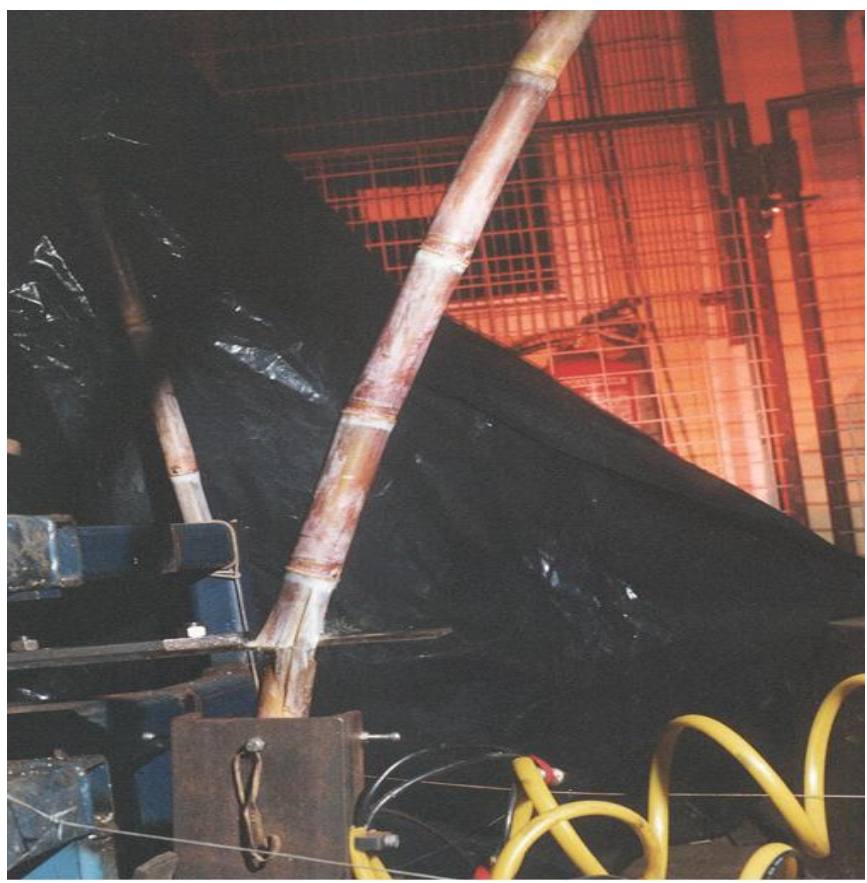

Figura 7. Corte com lâmina standard 


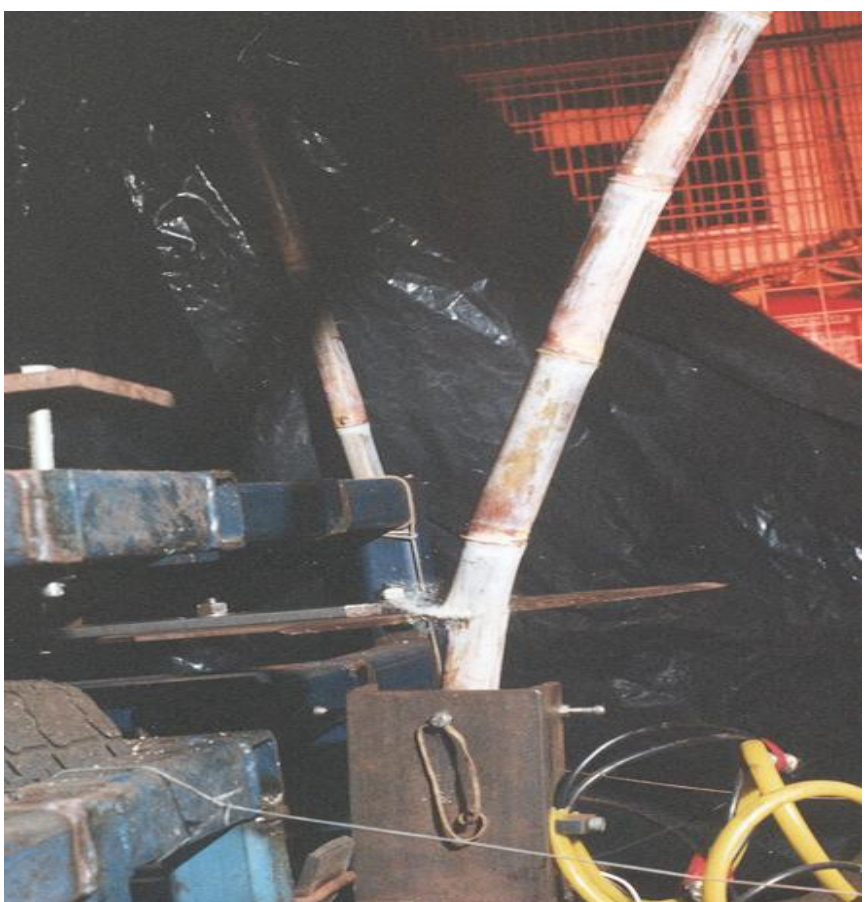

Figura 8. Corte com lâmina inclinada para trás

A lâmina inclinada para frente foi a que apresentou melhor desempenho. Com a combinação entre esta lâmina com o passo do serrilhado de $3 \mathrm{~mm}$, foi possível de se obter, em algumas repetições, um corte perfeito, classificado como número 1 , ou seja, sem danos, conforme Figura 9.

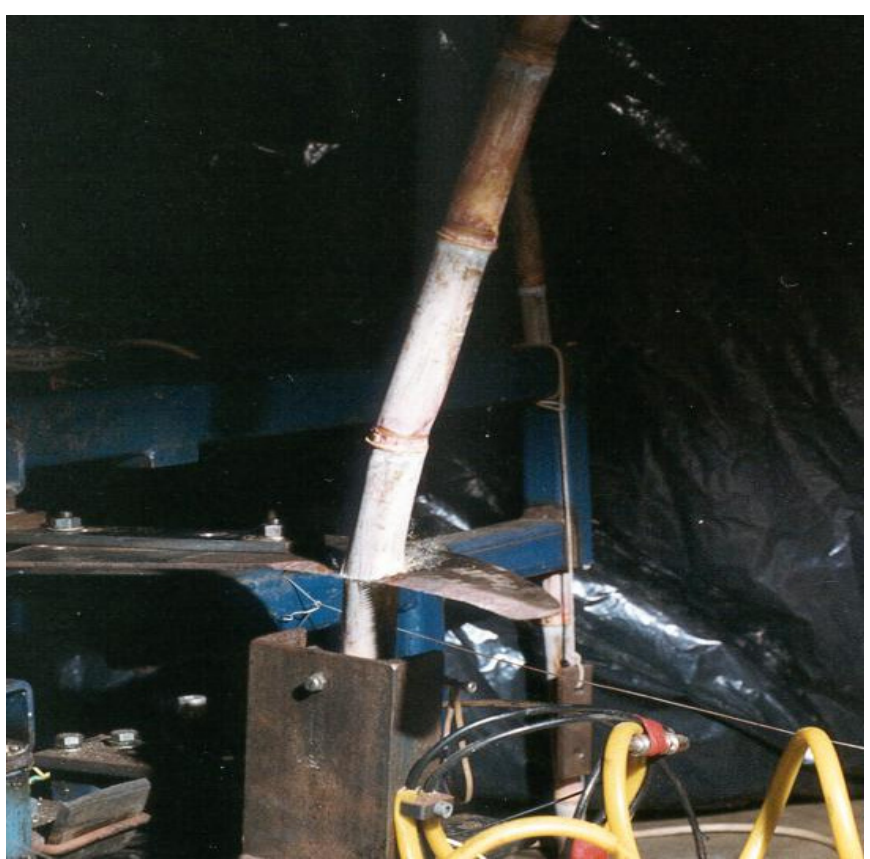

Figura 9. Corte com lâmina inclinada para frente

A preocupação com o serrilhado de passo de $3 \mathrm{~mm}$ é o fato desses se desgastarem muito rapidamente em cortadores de base, visto que trabalham próximos ou em contacto com o solo; portanto, para trabalhos de campo é recomendado um corte levemente acima da superfície do solo, a fim de evitar desgaste prematuro.
Quanto aos resultados, a energia específica não apresentou diferenças significativas. A média obtida neste teste foi de 2,18 $\mathrm{J} \mathrm{cm}^{-2}$, com um coeficiente de variação de $36 \%$.

Os dados da Tabela 1 (valores médios das quatro repetições) mostram que houve diferenças significativas para os danos causados à cana, em que as lâminas standard apresentaram um dano médio de 4,5 e o melhor corte foi para a combinação entre as lâminas inclinadas para frente, com o passo serrilhado de $3 \mathrm{~mm}$, que apresentou dano médio de 1,5.

Tabela 1. Classificação dos danos causados à cana em função do tipo de lâmina

\begin{tabular}{lccc}
\multirow{2}{*}{ Lâmina } & $\begin{array}{c}\text { Média } \\
\text { (Classificada) }\end{array}$ & \multicolumn{2}{c}{ Significância $(\%)$} \\
\cline { 3 - 4 } & 4,50 & 5 & 1 \\
\hline Standard & 3,00 & $\mathrm{~B}$ & $\mathrm{~A}$ \\
Inclin. trás $7 \mathrm{~mm}$ & 2,75 & $\mathrm{~B}$ & $\mathrm{~B}$ \\
Inclin. trás $3 \mathrm{~mm}$ & 2,75 & $\mathrm{~B}$ & $\mathrm{BC}$ \\
Inclin. frente $7 \mathrm{~mm}$ & 1,50 & $\mathrm{C}$ & $\mathrm{C}$ \\
Inclin. frente $3 \mathrm{~mm}$ & & & \\
\hline
\end{tabular}

\section{CONCLUSÕES}

1. Na presença de momento fletor, as lâminas inclinadas para frente apresentaram melhor desempenho que as lâminas standard e as inclinadas para trás.

2. O passo de $3 \mathrm{~mm}$ do perfil serrilhado foi o que apresentou o melhor resultado.

3. Foi possível se obter um corte perfeito na presença de momento fletor, com a combinação da lâmina inclinada para frente, com o perfil serrilhado de $3 \mathrm{~mm}$.

4. Com uma simples modificação no disco do cortador de base, é possível de se adaptar lâminas inclinadas, em qualquer colhedora comercial, a um custo extremamente baixo.

\section{AGRADECIMENTOS}

Ao Sugar Research and Development Corporation, pelo suporte financeiro para o desnvolvimento do projeto. À FAPESP, pela bolsa parcial para o pagamento das taxas universitárias.

\section{LITERATURA CITADA}

Chancellor, W.J. Basic concepts of cutting hay. Ithaca: Cornell University, 1957. 186p. Ph.D. Thesis

Harris, H.D.; Mello, R. da C. Kinematics, blade shapes and edges for alternative basecutter configurations. Conference of Australia Society of Sugarcane Technologists 21. 1999, Townsville. Proceedings... Townsville, 1999, p.185-190

Kroes, S. The cutting of sugarcane. Toowoomba: University of Southern Queensland, 1997.356p Ph.D. Thesis

Mello, R. da C. Improvements in basecutter design and cane feeding. Toowoomba: University of Southern Queensland, 2003. 220p. Ph.D. Thesis

Persson, S. Mechanics of cutting plant material. Michigan, American Society of Agricultural Engineers, 1987. 288p.

Ueno, N.; Izumi, H. Sugar Loss due to mechanical harvesting. Conference International Society of Sugar Cane Technologists. 21, 1995. New Delhi. Proceedings... New Delphi, 1995, p.274-285. 